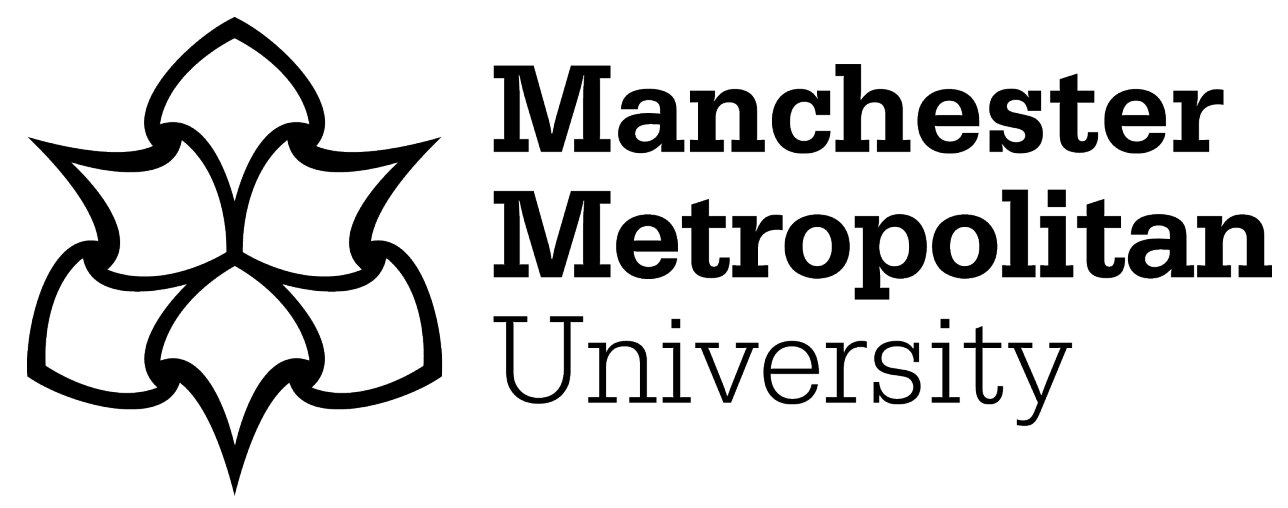

Giladi, Paul (2016) New Directions for Transcendental Claims. Grazer Philosophische Studien, 93 (2). pp. 212-231. ISSN 0165-9227

Downloaded from: https://e-space.mmu.ac.uk/621126/

Version: Accepted Version

Publisher: Brill

DOI: https://doi.org/10.1163/18756735-09302006

Please cite the published version 


\section{New Directions for Transcendental Claims}

Keywords: transcendental claims; transcendental arguments; epistemology; post-Kantian philosophy

This paper aims to provide an account of the relationship between transcendental claims and the project of using transcendental argumentation that differs from the mainstream literature. ${ }^{1}$ By a 'transcendental claim', I mean a proposition which states that $y$ is a necessary condition for the possibility of $x .^{2}$ In much of the literature, such claims are said to have as their primary value the overcoming of various sceptical positions. I argue that whilst transcendental arguments may be narrowly characterised as anti-sceptical, transcendental claims do not have to be used in only this way, and in fact can be useful in several areas of philosophy outside the issue of scepticism, and so can be used by transcendental arguments more broadly conceived. I offer four examples of transcendental claims that are not used in narrow, anti-sceptical transcendental arguments. I argue that these broader arguments use transcendental claims but not in an anti-sceptical way. From this, I conclude that one can separate the project of making transcendental claims and the project of using transcendental arguments to defeat scepticism. Given the well-known difficulties transcendental arguments in this narrow sense seem to have had in defeating scepticism, ${ }^{3}$ distinguishing narrow transcendental arguments clearly from transcendental claims as such in this manner can provide a way for the latter to still serve an important role in philosophy, by showing how such claims can be used more broadly, regardless of any doubts one may have about the antisceptical value of such claims.

\footnotetext{
${ }^{1}$ Cassam (1987, 1997, 1999), Franks (1999, 2005), Grayling (1985), Körner (1966), Peacocke (1989), Sacks (1999, 2005a, 2005b), Stapelford (2008), Stern (2000, 2007, 2011), Strawson (1959, 1966, 1985), Stroud (1968, 1999, 2000), Walker (1989).

${ }^{2}$ Of course, the sense of a necessity in a transcendental claim is not a mere causal necessity. The question then is whether it is apt to regard transcendental claims as having their apodictic content in terms of logical necessity or metaphysical necessity. Those who argue that the sense of necessity is logical necessity are Bennett (1979), Bell (1999), Walker $(1978,1989)$. However, most philosophers who are interested in transcendental claims are more inclined to suggest that the sense of necessity is not logical, but rather some kind of metaphysical necessity. I take the 'necessary condition for the possibility of $x$ ' clause to mean that $y$ is not just a necessary condition for $x$ being actual, but for $x$ being possible; so obtaining in any possible world, not just this one. This is why a transcendental claim is a claim concerning the necessary conditions for the possibility of $x$ as opposed to just being a necessary condition for $x$. Understood in this way, my definition of a transcendental claim does not entail that all necessity claims count as transcendental, because the sense of necessity involved in a transcendental claim is stronger than natural necessity.

${ }^{3}$ For the problems that face the use of transcendental arguments to defeat scepticism, see Körner (1966), Stroud (1968), Hookway (1999), and Stern (1999, 2000, 2007).
} 
A transcendental argument, as typically understood, is a deductive argument designed to establish that $p$, by arguing from $q$, and the claim that $p$ is a necessary condition for the possibility of $q$. Typically, the approach of transcendental arguments begins with a noncontroversial starting point, $q$, where a characteristic starting point would be a fact about how human beings think about, judge or experience certain things, including ourselves. The argument then proceeds from this kind of claim to a more controversial claim, where this kind of proposition is a transcendental claim, the claim that plays the role of the second premise. A transcendental claim is one which states that $p$ is a necessary condition for the possibility of $q$. As Robert Stern writes, "the form of the argument is: we have certain experiences etc.; a necessary condition for us having these experiences etc. is the truth of [p]; therefore [p]" (Stern 2007, 144). One example of such a claim is the proposition that we experience things in space and time.

Now, according to P. F. Strawson, "the point of transcendental arguments in general is an anti-sceptical point" (Strawson 1985, 10). ${ }^{4}$ I take this to mean the following: (i) the target of a transcendental argument is some kind of sceptic, where depending on the specific dialectical context, this sceptic could be a sceptic about other minds, a sceptic about knowledge claims of a mind-independent external world, a moral sceptic, etc.; (ii) the value of a transcendental argument principally consists in the argument's ability to successfully defeat the relevant sceptical position.

To see transcendental arguments in action, we would perhaps do well to briefly look at the structure of Kant's argument in the Refutation of Idealism, which appears to be a locus classicus of transcendental argumentation: ${ }^{5}$

I am conscious of my own existence as determined in time. All determination in regard to time presupposes the existence of something permanent in perception. But this permanent something cannot be something in me, for the very reason that my existence in time is itself determined by this permanent something. It follows that the perception of this permanent existence is possible only through a thing without me and not through the mere representation of a thing without me. Consequently, the determination of my existence in time is possible only through the existence of real things external to me. Now, consciousness in time is necessarily connected with the consciousness of the

\footnotetext{
${ }^{4}$ Compare Strawson's remark here with a remark from Jonathan Lear and Barry Stroud: “... the value of a transcendental argument is thought to consist in its ability to combat scepticism" (Lear and Stroud 1984, 219).

${ }^{5}$ There are two things which need to be noted here: firstly, Bell (1999) questions whether the Refutation of Idealism is in fact a transcendental argument at all. Secondly, there is a general issue of whether or not it is possible to talk about transcendental arguments from outside the concerns of transcendental idealism or even Kantianism tout court. For discussion of whether transcendental arguments found a place other than in transcendental idealism, see Beiser (2005), Franks (1999, 2005), and Taylor (1972).
} 
possibility of this determination in time. Hence it follows that consciousness in time is necessarily connected also with the existence of things without me, inasmuch as the existence of these things is the condition of determination in time. That is to say, the consciousness of my own existence is at the same time an immediate consciousness of the existence of other things without me. (B275-6)

In the Critique of Pure Reason, the Refutation of Idealism is directed at the "problematic idealism of Descartes", which claims that the existence of mind-independent objects in space is subject to sceptical doubt. Kant begins his argument with a claim which the sceptic accepts, namely that we are self-conscious and aware of our inner mental episodes as having a temporal order. The argument of the Refutation then proceeds to show that we cannot be self-conscious and aware of our inner mental episodes as having a temporal order unless there really does exist an external world. Using Stern's formulation of the argument enables us to see its exact details: ${ }^{6}$

(1) You are aware of your inner mental states (thoughts and sensations) as having a temporal order (e.g., that the sensation of pain you are having now was preceded in time by a feeling of pleasure).

(2) To be aware of your mental states as having a temporal order, you must be aware of something that existed from the time of your previous mental state to the present.

(3) For that awareness of permanence to be possible, it is not sufficient to have awareness of your self.

(4) Therefore, the "permanent" of which you are aware must be something that is neither you qua subject nor your subjective impressions but must be something distinct from both of these, that is, an object outside you in the external world.

(5) Therefore, your awareness of the external world cannot come from a prior awareness of your subjective impressions because the latter awareness is not possible without the former, and so awareness of the external world cannot be based on the imagination but rather comes from generally veridical experiences.

By starting with a premise which the sceptic accepts, the sceptic is led through transcendental claims which she must accept if she is to remain committed to (1). ${ }^{7}$ Thus, the sceptic is

\footnotetext{
${ }^{6} \mathrm{R}$. Stern, http://plato.stanford.edu/entries/transcendental-arguments/

${ }^{7}$ Another kind of sceptic, however, may wish to resist (1). Prima facie, this means that Kant's transcendental argument is powerless against more radical forms of scepticism, such as scepticism about the validity of laws of logic. But even if Kant's transcendental argument is powerless against more radical scepticism, it is far from
} 
refuted on the grounds that she must presuppose what in fact she seeks to deny. As Kant himself writes, "[we] turn the game played by idealism against itself” (B276). ${ }^{8}$

What our overview of the structure of a transcendental argument has revealed so far is that as a matter of fact their use has often been anti-sceptical, and indeed this is taken as definitive of them in some quarters. However, one may well now ask whether having an antisceptical function and having an anti-sceptical value is constitutive of the project of transcendental argumentation. Let us call this 'The Constitutive Question'. I think there are no compelling reasons to think transcendental arguments sans phrase are constitutively directed at sceptics, since the formal schema of a transcendental argument through which such arguments are defined - to establish that $p$, by arguing from $q$, and the claim that $p$ is a necessary condition for the possibility of $q$-does not specify $p$ and $q$ as such. .

However, that being said, there is one genus of transcendental argument that is characteristically designed to be anti-sceptical, one which may be dubbed as narrow transcendental argumentation: here, the transcendental argument is supposed to begin with a premise that no reasonable sceptic can doubt. The putative advantage of such a starting point is that the proponent of the relevant transcendental argument refutes the sceptic in a head-on manner without the problems of bringing in any other epistemological commitments or further philosophical ideas. In other words, the structure of a transcendental argument is designed to prevent any question-begging claims against the sceptics or anything else that the sceptic would likely reject, because what the transcendental argument aims to do is show that scepticism is incoherent on its own terms. ${ }^{9}$ Secondly, another feature of narrow transcendental arguments is the deductively valid logical form of these arguments. For, whilst narrow transcendental arguments make use of empirical claims in some non-controversial starting points, the conclusion of a narrow transcendental argument is meant to deductively follow from the premises, in order to reject the relevant sceptical position. Such arguments may thus seem to have greater anti-sceptical force than any more inductive or abductive

obvious that the transcendental argument's inability to shift the sceptic from the sceptic's position is a weakness or even failing on the part of the transcendental argument. This is because one has compelling reason to regard radical forms of scepticism as unintelligible themselves, given how little basic dialectical ground they are prepared to give the transcendental theorist or for that matter any anti-sceptical position simpliciter.

${ }^{8}$ A classic example of an analytic transcendental argument is Strawson's 'objectivity argument' in The Bounds of Sense, cf. (Strawson 1966, 97-112). Furthermore, one could also understand Wittgenstein's Private Language Argument as an example of a transcendental argument. However, this kind of interpretation of Wittgenstein's concerns in that argument is usually based on Saul Kripke's reading of the Private Language Argument, cf. Kripke (1982).

9 As Strawson writes, “[the sceptic's] doubts are unreal, not simply because they are logically unresolvable doubts, but because they amount to the rejection of the whole conceptual scheme within which alone such doubts make sense". (Strawson 1959, 35) 
approach. Thirdly, the kinds of question that a narrow transcendental argument aims to answer are justificatory challenges to the anti-sceptic, where failing to justify how knowledge is possible or how morality is possible will inevitably lead to scepticism about those kinds of phenomena. One might wish to claim that the kinds of questions narrow transcendental arguments are designed to answer are in fact rather ambiguous, to the extent that asking how $\mathrm{x}$ is possible can also be taken to herald a descriptivelexplanatory challenge for the antisceptic to explain to other anti-sceptics why/how we have knowledge or why/how we are able to be moral. However, it is not clear that such a descriptive question can ever be genuinely separated from the justificatory question. For example, in the Critique of Pure Reason, Kant began asking how we have synthetic a priori knowledge in terms of providing an explanation for how such knowledge is possible for us given our cognitive architecture. However, the question concerning the possibility of synthetic a priori knowledge is quickly transformed into the justificatory challenge of providing persuasive reasons to think that we are justified in thinking we have such a kind of knowledge. Given these various considerations, it seems not just that as a matter of fact narrow transcendental arguments have been anti-sceptical, but that it is in the nature of such arguments to be so.

Thus far, we have seen that some transcendental arguments may be characteristically antisceptical, because of the nature of their starting points, the logical structure of the arguments, and the particular kind of question they are designed to answer. However, one may now ask whether transcendental claims have to be anti-sceptical. For, if there is compelling reason to think that transcendental claims do not have to be anti-sceptical, then we have compelling reason to think that the project of making transcendental claims can be separated from the project of narrow transcendental argumentation, leaving open the possibility of transcendental arguments using those claims that at the same time are not anti-sceptical in nature. In other words, whilst the project of narrow transcendental argumentation constitutively involves situating transcendental claims within the framework of an antisceptical transcendental argument, the project of making transcendental claims does not constitutively involve situating those propositions within the framework of a narrow transcendental argument. It is to this issue that I now wish to turn. 
II

The first transcendental claim I would like to draw attention to is Hegel's idea in the Phenomenology of Spirit that conceptual articulation is a necessary condition for the possibility of language. Consider the following from Charles Taylor, who writes:

The new theory of language that arises at the end of the eighteenth century, most notably in the work of Herder and Humboldt, not only gives a new account of how language is essential to human thought, but also places the capacity to speak not simply in the individual but primarily in the speech community. This totally upsets the outlook of the mainstream epistemological tradition. Now arguments to this effect have formed part of the refutation of atomism that has proceeded through an overturning of standard modern epistemology.

Important examples of arguments of this kind are Hegel's in the first chapter of the Phenomenology of Spirit, against the position he defines as "sensible certainty," where he shows both the indispensability of language and its holistic character; and Wittgenstein's famous demonstrations of the uselessness of "ostensive definitions," where he makes plain the crucial role played by language in identifying the object and the impossibility of a purely private language. Both are, I believe, excellent examples of arguments that explore the conditions of intentionality and show their conclusions to be inescapable. (Taylor 1987, 13)

According to Taylor, an important feature of Hegel's discussion of Sense-Certainty is Hegel's aim to show how the necessary conditions for the possibility of language render the position of Sense-Certainty incoherent. Crucially, though, Hegel does not use the transcendental claim - that having and exercising conceptual capacities is a necessary condition for the possibility of language - in order to target and then refute a sceptic who claims that language is not possible. For, Hegel's target ${ }^{10}$ in the opening chapter of the Phenomenology is someone who thinks that reference is possible by virtue of providing ostensive definitions. ${ }^{11}$ In other words, according to the Sense-Certainty theorist, I am able to pick out individual objects and label such objects as those objects simply by pointing to those and only using ostensive indexicals. As Robert Pippin writes, “... the goal [of Hegel's argument] is obviously to demonstrate that even the simplest form of demonstrative reference

\footnotetext{
${ }^{10}$ Someone may claim that there seems very little to prevent one from thinking that Hegel's target is a sceptic of sorts, where the sense-certainty theorist is seen as a sceptic about the social nature of language. As such, there would then be no compelling ground to clearly differentiate the targets of transcendental arguments and the targets of the project of making transcendental claims. In response to this, I do not think there is good reason to suppose that the sense-certainty theorist can be portrayed as a sceptic. My worry is that scepticism is being understood in such ways that pretty much every philosophical position is a sceptical position of sorts: nominalists are sceptics about universals; realists are sceptics about nominalist metaphysics; non-conceptualists are sceptics about conceptual content; conceptualists are sceptics about non-conceptual content.

${ }^{11}$ For further on Hegel's transcendental concerns in Sense-Certainty, see Taylor (1972), Dulckeit (1986), Pippin (1989), Pinkard (1994), Stern (2012), and Houlgate (forthcoming).
} 
would not be possible without some describing capacity, a capacity that requires descriptive terms or predicates ... not merely deictic expressions and atomic objects" (Pippin 1989, 117). To see how this works, let us briefly consider Hegel's argument: according to the sensecertainty theorist, I can pick out and refer to an individual object by pointing to it and dubbing it the here-and-now. For sense-certainty, here-and-now is meant to capture a unique feature of an object and thus enable me to refer to that individual object. However, Hegel proceeds to argue that being here-and-now is far from unique to the object, as different times and places can come be to be here-and-now, and thus so can different things. Sense-certainty, therefore, has failed to properly refer to this particular object by virtue of picking out its singular individuality, because all that sense-certainty has been able to do is to pick out a property that can belong to many individuals, a property which is universal. ${ }^{12}$ Not only that, the ultimate problem with sense-certainty's commitment to referring to individual objects without reference to concepts - what Hegel calls apprehension - is that the non-conceptual 'describing' capacities fail to refer simpliciter, because what we discover in the dialectic of sense-certainty is that concepts and a holistic logico-linguistic framework ${ }^{13}$ are necessary conditions for the possibility of language and that sense-certainty therefore can be refuted on grounds that it violates the necessary conditions for the possibility of language and is thus incoherent. In this instance at least, we have found a transcendental claim that is not situated within the framework of narrow transcendental argumentation.

Consider now another Hegelian argument, one which appears to argue for a transcendental claim concerning the metaphysical structure of infinity:

[It is said that] the infinite, one the one side, exists by itself, and that the finite has gone forth from it into a separate existence ...; but it should rather be said that this separation is incomprehensible ... But equally it must be said that they are comprehensible, to grasp them even as they are in ordinary conception, to see that in the one there lies the determination of the other ... is to see the simple insight into their inseparability ... This unity of the finite and infinite and the distinction between them are just as inseparable as are finitude and infinity. (Science of Logic: 153-154)

\footnotetext{
12 “...in this simplicity [Now] is indifferent to what happens in it; just as little as Night and Day are its being, just as much also is it Day and Night; it is not in the least affected by this its other-being. A simple thing of this kind which is through negation, which is neither This nor That, a not-This, and is with equal indifference This as well as That - such a thing we call a universal. So it is in fact the universal that is the true [content] of sensecertainty... The same will be the case with the other form of 'This', with 'Here'. 'Here' is e.g., the tree. If I turn round, this truth has vanished and is converted into its opposite: 'No tree is here, but a house instead'. 'Here' itself does not vanish; on the contrary, it abides constant in the vanishing of the house, the tree, etc., and is indifferently house or tree. Again, therefore, the 'This' shows itself to be a mediated simplicity, or a universality... [S]ense-certainty has demonstrated in its own self that the truth of its object is the universal." (Phenomenology of Spirit: 60-61)

13 By this, I mean being endowed with capacities that enable us to draw distinctions and similarities determinate negations - and relations between things - formal and informal inferences.
} 
From the above passage, we can construct the following argument:

(1) If the finite is separate from the infinite, then there is something outside of the infinite.

(2) There is nothing outside of the infinite.

(3) Therefore, the finite is not separate from the infinite.

As we can see from my formulation of Hegel's argument, his argument is one which has neither the dialectical function of a narrow transcendental argument nor the logical structure of a narrow transcendental argument. ${ }^{14}$ For, Hegel is concerned with dismissing the claims of pre-Kantian rationalists as metaphysical conjecture, since if the infinite were understood in opposition to the finite, then the infinite would be finite itself, because it would be limited by the finite. "There would then be per impossibile a greater reality than the infinite. Hence, the true infinite must therefore include the finite" (Beiser 2005, 142). I think that, given Hegel's concerns here, there is very good reason to regard his argument as using a metaphysical transcendental claim for a non-sceptical effect, to argue that the finite does not lie outside the infinite.

Thus far, we have seen the use of transcendental claims independently of the project of narrow transcendental argumentation by understanding transcendental claims as having a function and value in the domain of epistemology/philosophy of mind and in the domain of metaphysics. I now wish to discuss another instance of a transcendental claim not being used for anti-sceptical purposes. In what follows, I argue that we can interpret Paul Grice's Cooperative Principle and his norms of conversation as comprising transcendental claims and that these transcendental claims do not form any part of any narrow transcendental argument.

\footnotetext{
${ }^{14}$ Another example of the presence of transcendental claims in the domain of metaphysics is Hegel's discussion of Spinoza's 'All Determination is Negation' Principle. For Hegel, the negation that accompanies determination is a necessary condition for the possibility of being in any genuine sense. In other words, Hegel claims that if anything is to be, then it must have determination and so negation. His argument can be understood as follows: for anything to be more than just a completely formal and abstract pure being, which for Hegel is the same as nothingness, there must be some kind of determination. Such determination must involve some negation. As Stern writes, "the principle thus plays an important role within Hegel's ontological position, where it is crucial to his case against Parmenidean monism, which treats reality as a 'one', lacking in any element of difference; rather, Hegel argues, reality must incorporate some element of differentiation, of distinctions within being, where without these 'negations' it would not comprise determinate being, but would be no more than the nothingness of pure being". (Stern, forthcoming, 2) Now, there seems to be good reason to interpret Hegel's use of the 'all determination is negation' principle as a transcendental claim: here, Hegel is interested in establishing the necessary conditions for the possibility of being as being proper.

It is important to note here that Stern emphasises that the way Hegel understands the 'All Determination is Negation' principle seems to be the opposite of the way in which Spinoza himself understands it.
} 
Grice (1975, 26-30) proposed a general Cooperative Principle, which is composed of four norms governing proper linguistic interaction with fellow speakers:

Cooperative Principle: Contribute what is required by the accepted purpose of the conversation.

Maxim of Quality: Make your contribution true; so do not convey what you believe false or unjustified.

Maxim of Quantity: Be as informative as required.

Maxim of Relation: Be relevant.

Maxim of Manner: Be perspicuous; so avoid obscurity and ambiguity, and strive for brevity and order.

Grice does not take these norms of assertion which constitute the Cooperative Principle to be mere socio-linguistic conventions. Rather, Grice regards these norms of assertion which constitute the Cooperative to represent necessary conditions for the possibility of proper conversation between competent language users. As Grice writes,

The presence of a conversational implicature must be capable of being worked out; for even if it can in fact be intuitively grasped, unless the intuition is replaceable by an argument, the implicature (if present at all) will not count as a conversational implicature; it will be a conventional implicature. To work out that a particular conversational implicature is present, the hearer will rely on the following data: (1) the conventional meaning of the words used, together with the identity of any references that may be involved; (2) the Cooperative Principle and its maxims; (3) the context, linguistic or otherwise, of the utterance; (4) other items of background knowledge; and (5) the fact (or supposed fact) that all relevant items falling under the previous headings are available to both participants and both participants know or assume this to be the case. A general pattern for the working-out of a conversational implicature might be given as follows: He has said that q; there is no reason to suppose that he is not observing the maxims, or at least the Cooperative Principle; he could not be doing this unless he thought that p; he knows (and knows that I know that he knows) that I can see that the supposition that he thinks that $p$ is required; he has done nothing to stop me thinking that $\mathrm{p}$; he intends me to think, or is at least willing to allow me to think, that $\mathrm{p}$; and so he has implicated that p. (Grice 1975, 31)

To see why the Cooperative Principle and its norms of assertion are transcendental claims, consider the following scene from The Last Samurai: Captain Nathan Algren has recently been captured by the Samurai Lord Katsumoto. After several weeks of being slowly nursed 
back to health having suffered injuries in a skirmish with Katsumoto's warriors, Algren is summoned to meet Katsumoto. The Samurai Lord, upon seeing Algren enter his quarters, rises from his meditative position on the floor and formally introduces himself to the American officer: "My name is Katsumoto. What is your name?" Algren does not reply. Taken slightly aback by the American's refusal to reciprocate formal courtesies, Katsumoto then says the following: "Many of our customs seem strange to you. And the same is true of yours. For example, not introducing yourself is considered extremely rude, even among enemies". After a brief pause, Algren then replies to Katsumoto giving him his rank and full name. Having seen his formal introduction reciprocated, Katsumoto then informs Algren that: "I have introduced myself. You have introduced yourself. This is a very good conversation". What is relevant to our discussion here is that Katsumoto only regards his linguistic interaction with Algren to amount to a proper conversation - what he claims to be a "very good conversation" - once the American officer reciprocates the relevant implicatures in the various speech acts. It is not just that Algren is being rude and rather uncouth by not following the relevant norms of conversation here, it is also that Katsumoto does not think that the two language users can be in the position of having a conversation unless the Cooperative Principle is adhered to by both parties. ${ }^{15}$

Given what I have just written, it may seem implausible to think that unless Algren adheres to the Cooperative Principle, then he and Katsumoto cannot have a conversation. For, we can suppose that Algren had lied about his rank, etc. In such a case, they would be having a conversation, but not a good one. However, the problem with this objection is its conflation of having a conversation with exchanging words with another competent language-user: Algren lying about his rank when replying to Katsumoto's request obviously constitutes him speaking to Katsumoto, but it does not appear to constitute conversing with Katsumoto. When Katsumoto says that his linguistic interaction with Algren is a very good conversation, he is not meaning that it is a conversation that has given him a lot of pleasure and enjoyment. Rather, his use of the normative property 'good' is meant to express his gratitude to Algren for having made their linguistic interaction now a bona fide conversation. To this extent, the Cooperative Principle and its constituent maxims function as necessary conditions for the possibility of such communication.

${ }^{15}$ This is linked to the idea that conversation must involve sharing of knowledge. 
The final example I wish to discuss concerns Knud Ejler Løgstrup's views on trust in his Ethical Demand. According to Løgstrup, trust is more basic than mistrust. As he writes in the following passages:

It is characteristic of human life that we normally encounter one another with natural trust ... Initially we believe one another's word; initially we trust one another. This may indeed seem strange, but it is part of what it means to be human. Human life could hardly exist if it were otherwise. We would simply not be able to live; our life would be impaired and wither away if we were to suspect the other of thievery and falsehood from the very outset. (The Ethical Demand, 8-9)

While helpful in some ways, social conventions may also obscure the significance of trust, as these conventions reduce the level of what is expected of us. We need such conventions to give form to our lives, but their effect is to overlay the significance of trust - where children stand outside these conventions, and thus have a clearer view of trust. (The Ethical Demand, 19-20)

According to Stern, ${ }^{16}$ Løgstrup's treatment of trust involves a crucial question concerning how to understand his claim that trust is more basic than mistrust - that trust has priority over mistrust. For example, various kinds of priority are possible: ${ }^{17}$

1. Psychological: trust is the attitude we start out with, not distrust [developmental priority]

2. Transcendental: trust is warranted as the default attitude, grounded in the necessary conditions of our fundamental practices, distrust is not [rational priority]

3. Value: trust is a prima facie good, so distrust can only be a privation or deficient form of trust [axiological priority]

4. Ontological: that trust is possible is not a result of our social arrangements, but is essential to the proper functioning of human life itself, whereas distrust is not essential in this way [priority in being]

There is particularly compelling reason to think, as Stern does, that while we should understand Løgstrup's claim that trust is basic as primarily a thesis concerning the claims of axiological and ontological priority which need to be treated as interdependent, Løgstrup's

\footnotetext{
${ }^{16}$ See Stern (forthcoming 2016).

${ }^{17} \mathrm{Cf}$. Stern forthcoming 2016, 6 - where pages are referenced as the pages in the manuscript.
} 
complex position does nonetheless comprise a transcendental element. ${ }^{18}$ To see why, consider the following passage:

Let us imagine that we stand facing a destroyer who is trying to win us for his cause, but we know that he will shun no means in doing so and that he is not to be trusted. Face to face with the destroyer, we discover how much effort it takes to remain on our guard. The thought that, by talking things out, we would be able to dissuade the destroyer from his destructive enterprise keeps presenting itself; there is no eradicating it once and for all. We must keep telling ourselves that it is an illusion to think that we could talk things out, and must continually bear in mind that anything we say will be used to put a third vulnerable party out of the way. But why is that thought so persistent? Why do we need to make such an effort to restrain ourselves, and why do we experience doing so as nothing less than contrary to nature? It is because we are opposing the requirement inherent in speech that speech be open. To speak is to speak openly. The requirement comes from speech, springs from speech itself, is identical with its definitive character qua spontaneous expression of life, and is imposed by speech at the very instant in which I have recourse to it and realise myself in it ... If I deceive another or raise my guard, I challenge the definitive feature of speech which attaches to it in advance of, and independently of, me. (Beyond the Ethical Demand, 54$55)^{19}$

Here, we can see that Løgstrup draws a specific connection between speech and trust in the sense of 'openness' - where speech is understood qua the social practice of linguistic communication with another speaker. The connection consists in how speech is not possible unless there is general openness and trust between the relevant speakers. Such a claim appears to be a transcendental claim. As with the previous examples we have discussed, we can notice that a transcendental claim is being made but crucially that transcendental claim is being made independently of any narrow transcendental argument. What this means is that

\footnotetext{
${ }^{18}$ See the following from Stern:

"It should be clear, therefore, that on Løgstrup's account, the claims of axiological and ontological priority need to be thought together: the latter claim is not a value neutral one, for example like the claim that individuals are prior to social agents as the latter are not possible without the former. Rather, the ontological priority of trust stems from the fact that trust is a requirement or condition for the proper functioning of human life, which is what makes it something we do not create ourselves (ontological priority), but also makes it a fundamental good and thus prior in this sense too, as having a value that is also not attributed to it by us (axiological priority).

This also shows why the two kinds of priority we rejected - psychological and transcendental - may nonetheless come to have some place in Løgstrup's account in a suitably modified way. For while we argued that Løgstrup's view does not operate at just a psychological level, and we can now see why, nonetheless we can also see why he appeals to psychological evidence of the damaging effects of distrust on children and adults. And likewise, while we also argued that Løgstrup's view does not argue primarily for the rational priority of trust over distrust on the grounds that the latter makes the former possible, nonetheless his claims about the ontological priority of trust do nonetheless contain what might be thought of as a world-directed transcendental claim, namely that trust is a necessary condition to the proper functioning of human life on which distrust is parasitic, and thus is a normative structure in which we are grounded as a 'given', rather than something we create for ourselves and for which we can claim any credit" (Stern forthcoming 2016, 25).

${ }^{19}$ A similar point is made also in pp. 83-5.
} 
we can legitimately separate the project of making transcendental claims from the project of narrow transcendental argumentation - to put this more simply, our discussion has now enabled us to assert the following: a narrow transcendental argument necessarily involves the use of transcendental claims; but one can make transcendental claims independently of situating those kind of claims within the framework of narrow transcendental arguments.

Given this, though, one may well ask what the consequences of this discovery are for Kant's transcendentalism. One can recall how since the mid-1960s, there has been a concerted effort on the part of many analytic philosophers interested in Kant to separate the project of transcendental argumentation from transcendental idealism. But now, if what I have offered is convincing, there may now be a concerted effort to separate transcendental claims from the project of narrow transcendental argumentation. Where the battle-cry used to be to save transcendental arguments from the pitfalls of transcendental idealism, one may well now ask to save transcendental claims from the pitfalls of narrow transcendental argumentation.

I readily admit that the kind of direction I have taken with regard to transcendental claims and transcendental argumentation is certainly not an orthodox Kantian one. In fact, what I have proposed, particularly with regard to the two examples from Hegel I discussed, is a transformation of Kant's transcendentalism. It is not just that we are no longer binding transcendental claims to transcendental idealism, we are also no longer binding transcendental claims to any project aimed at defeating scepticism. Rather, the new directions for transcendentalism - making transcendental claims independently of the framework of a narrow transcendental argument - illustrate how this philosophical school of thought can make substantive and engaging contributions to areas of constructive philosophy from metaphysics to social epistemology. Such a new course is certainly strange for anyone with a penchant for orthodox Kantianism, but I think such a change of direction is not just desirable but maybe even necessary for the possibility of taking transcendentalism particularly seriously.

However, one might question the alleged pay-off of separating the project of making transcendental claims and the project of narrow transcendental argumentation. One may well ask if the project of making transcendental claims is completely divorced from issues concerning the viability of the project of narrow transcendental argumentation. For example, one major issue in the literature on transcendental arguments is whether it is more plausible to regard transcendental arguments as being self-directed or as being world-directed. In other 
words, whether a transcendental argument should be understood as establishing the necessary conditions for the possibility of language or our use of certain concepts, or whether a transcendental argument should be understood as establishing facts about the structure of reality. It is often taken as granted that a transcendental argument can only and should only aspire to establish self-directed conclusions, such as 'We must think that there is a mindindependent external world', as the sceptic would only be prepared to accept this sort of conclusion rather than a conclusion which stated 'There is an external world'. However, even though the project of making transcendental claims is not concerned with defeating sceptical positions, one might think that there are different but still related concerns for what kinds of transcendental claims we are able to make and what kinds of transcendental claims have greater value. For example, can we only make comparatively fewer world-directed transcendental claims than self-directed transcendental claims? One can note that the kind of transcendental claim I have predominantly focused on in this paper seems to be a selfdirected transcendental claim, as most of my examples have been interested in issues concerning the conditions of reference, the conditions of language, and the conditions of proper conversation. ${ }^{20}$ If we can only make more self-directed transcendental claims then we can world-directed transcendental claims, does this mean that the project of making selfdirected transcendental claims is more valuable than the project of making world-directed transcendental claims? Is it potentially less valuable in some way if we focus on modalities concerning our capacities than if we focus on modalities concerning the structure of certain metaphysical phenomena? Furthermore, can we really ever avoid Körner's objection that it seems almost impossible to get the data from empirical and cognitive science that shows that transcendental claims really do have apodictic modal content, for even though Körner focused his critique on transcendental arguments and their apparent ability to defeat scepticism, there seems no reason to think his general criticism cannot equally apply to the project of making transcendental claims?

I cannot answer all these questions properly due to the constraints of this paper. However, what I would like to do is briefly explicate which approach I would favour. As we are no longer dealing with narrow transcendental arguments but just transcendental claims, the sceptic about knowledge of the external world or the sceptic about the possibility of morality - to name but a few sceptical positions - is now off the dialectical scene. As such, there is no

\footnotetext{
${ }^{20}$ An example of a world-directed transcendental claim could be Hegel's theory of infinity, which was sketched out on pp. 7-8. Another example of a world-directed transcendental claim could also be Hegel's understanding of the Spinozist principle 'All Determination is Negation'. I have briefly discussed this in footnote 14.
} 
obligation on the part of the exponent of transcendental philosophy to frame transcendental claims in such a way as to satisfy the sceptic. Of course, this sets the bar partially lower, to the extent that if one wishes to object to world-directed transcendental claims, these worries would have to come from more general worries anyone might have regarding the modal claims involved. As such, if my arguments have been successful, the new target of the project of making transcendental claims could be someone like Körner who, rather than be principally concerned with the idea that the transcendental claim is literally true, is more concerned with the idea that we can find the relevant data from empirical and cognitive science to support the notion that these claims really are necessary claims. However, one may wish to claim that modal claims involved in self-directed transcendental claims are easier to settle than those involved in world-directed transcendental claims. The reason for this could be that it is easier and apparently less problematic to establish apodictic claims about ourselves than facts about the world. However, I am not convinced that this Cartesian way of suggesting that the modal content of self-directed transcendental claims is less problematic than the modal content of world-directed transcendental claims is well justified. For, it is not clear to me that there is good reason to suppose that psychological facts are in fact less problematic or easier to settle than non-psychological facts. To suggest that the domain of psychological facts is free from the difficulties associated with the domain of nonpsychological facts appears to be dogmatic. ${ }^{21}$

If what I have argued has been persuasive, then it would seem that there are reasons to have hope for transcendental philosophy and also potentially despair for transcendental philosophy. One positive pay-off from separating the project of making transcendental claims from the project of narrow transcendental argumentation is that the sceptic is no longer a figure of dialectical concern. The transcendental theorist, therefore in a way, is less inhibited and now freer to conduct investigations into transcendental claims in the knowledge that she does not have to deal with the sceptic at all. Another positive pay-off is that one can notice just how interesting transcendental claims are independently of any anti-sceptical framework. However, for all of the putative attractions of the project of making transcendental claims, it seems that the transcendental theorist has merely exchanged one set of apparently intractable and debilitating problems for another set of apparently intractable and debilitating problems. All that has been achieved is simply jumping out of the frying pan and into the fire. Of course, I am not claiming that this new direction for transcendental claims is problem-free,

\footnotetext{
${ }^{21}$ For further on this, see Stern (2007).
} 
but what I hope one can now do with the project of making transcendental claims is open an engaging debate that highlights the importance and value of the kinds of issues raised in making transcendental claims independently of framing those claims in the context of defeating scepticism. 


\section{References}

Beiser, Frederick C. 2005: Hegel. New York \& London: Routledge.

Bell, David 1999: “Transcendental Arguments and Non-naturalistic Anti-realism”. In: Robert Stern (ed.), Transcendental Arguments: Problems and Prospects. Oxford: Oxford University Press, 189-210.

Bennett, Jonathan 1979: “Analytic Transcendental Arguments”. In Peter Bieri, Rolf-Peter. Horstmann \& Lorenz Krüger (eds.), Transcendental Arguments and Science: Essays in Epistemology. Dordrecht: Reidel, 45-64.

Cassam, Quassim 1987: “Transcendental Arguments, Transcendental Synthesis, and Transcendental Idealism”. The Philosophical Quarterly 37, 355-78.

--- 1997: Self and World: Oxford: Oxford University Press.

--- 1999: "Self-Directed Transcendental Arguments". In: Robert Stern (ed.) Transcendental Arguments: Problems and Prospects. Oxford: Oxford University Press, 83-110.

Dulckeit, Katerina 1986: “Can Hegel Refer to Particulars?”. The Owl of Minerva 17, 181194.

Franks, Paul 1999: "Transcendental Arguments, Reason, and Scepticism: Contemporary Debates and the Origins of Post-Kantianism". In: Robert Stern (ed.) Transcendental Arguments: Problems and Prospects. Oxford: Oxford University Press, 111-146.

--- 2005. All or Nothing: Systematicity, Transcendental Arguments, and Scepticism in German Idealism. Cambridge, Mass.: Harvard University Press.

Grayling, Anthony. C. 1985: The Refutation of Scepticism. London: Duckworth.

Grice, Paul H. 1975: "Logic and Conversation”. In: Peter Cole \& Jerry Morgan (eds.) Syntax and Semantics, 3: Speech Acts. New York, NY: Academic Press, 41-58.

Hegel, Georg. W. F. 1969: Science of Logic. A. V. Miller (trans.) London: Allen and Unwin.

--- 1977: Phenomenology of Spirit. A. V. Miller (trans.) Oxford: Oxford University Press.

Hookway, Christopher 1999: "Modest Sceptical Arguments and Sceptical Doubts: A Reply to Stroud". In Robert Stern (ed.) Transcendental Arguments: Problems and Prospects. Oxford: Oxford University Press, 173-188.

Houlgate, Stephen forthcoming: "Is Hegel's Phenomenology of Spirit an Essay in Transcendental Argument?”. In: Sebastian. Gardner (ed.) The Transcendental Turn. Oxford: Oxford University Press. 
Jacobi, Friedrich. H. 1994: The Main Philosophical Writings and the Novel 'Allwill'. G. di Giovanni (trans.) \& (ed.) Montreal/Kingston: McGill-Queen's University Press.

Kant, Immanuel 1997: Critique of Pure Reason. P. Guyer and A. Wood (trans.) Cambridge and New York: Cambridge University Press.

Körner, Stephan 1966: "Transcendental Tendencies in Recent Philosophy". Journal of Philosophy 63, 551-61.

--- 1967: “The Impossibility of Transcendental Deductions”. Monist 51, 317-31.

Kripke, Saul 1982: Wittgenstein on Rules and Private Language. Oxford: Blackwell.

Lear, Jonathan and Stroud, Barry 1984: "The Disappearing "We". Proceedings of the Aristotelian Society Supplementary Volumes 58, 219-258.

Løgstrup, Knud. E. 1997: The Ethical Demand. H. Fink and A. MacIntyre (eds.) Notre Dame, IN: Notre Dame University Press.

--- 2007: Beyond the Ethical Demand. K. van Kooten Niekerk (intro.) Notre Dame, IN: University of Notre Dame Press.

Peacocke, Christopher 1989: Transcendental Arguments in the Theory of Content. Oxford: Oxford University Press.

Pinkard, Terry 1994: Hegel's Phenomenology: The Sociality of Reason. Cambridge: Cambridge University Press.

Pippin, Robert. B. 1989: Hegel's Idealism: The Satisfactions of Self-Consciousness. Cambridge: Cambridge University Press.

Sacks, Mark 1999: “Transcendental Arguments and the Inference to Reality”. In: Robert Stern (ed.) Transcendental Arguments: Problems and Prospects. Oxford: Oxford University Press, 67-82.

--- 2000: Objectivity and Insight. Oxford: Oxford University Press.

--- 2005a: "The Nature of Transcendental Arguments". International Journal of Philosophical Studies 13, 439-60.

--- 2005b: "Sartre, Strawson and Others". Inquiry 48, 275-99.

Stapelford, Scott 2008: Kant's Transcendental Arguments: Disciplining Pure Reason. London: Continuum.

Stern, Robert (ed.) 1999: Transcendental Arguments: Problems and Prospects. Oxford: Oxford University Press.

--- 2000: Transcendental Arguments: Answering the Question of Justification. Oxford: Oxford University Press. 
--- 2007: “Transcendental Arguments: A Plea for Modesty”. Grazer Philosophische Studien $74,143-61$.

--- 2011: "The Value of Humanity: Reflections on Korsgaard's Transcendental Argument". In: Joel Smith \& Peter Sullivan (eds.) Transcendental Philosophy and Naturalism. Oxford: Oxford University Press.

--- 2012: 'Taylor, Transcendental Arguments, and Hegel on Consciousness'. Revista de Filosofia 132: 17-38.

--- forthcoming 2016: “"Trust is basic”: Løgstrup on the Priority of Trust over Distrust', in P. Faulkner and T. Simpson (eds.) New Perspectives on Trust. Oxford: Oxford University Press. --- "Transcendental Arguments", The Stanford Encyclopaedia of Philosophy, Edward N. Zalta (ed.), URL = <http://plato.stanford.edu/archives/sum2013/entries/transcendental$\operatorname{arguments} />$.

--- forthcoming: "Determination is Negation: The Adventures of a Doctrine from Spinoza to Hegel to the British Idealists". Hegel Bulletin.

Strawson, Peter F. 1959: Individuals: An Essay in Descriptive Metaphysics. London: Methuen.

--- 1966: The Bounds of Sense: An Essay on Kant's 'Critique of Pure Reason'. London: Methuen.

--- 1985: Scepticism and Naturalism: Some Varieties. London: Methuen.

Stroud, Barry 1968: “Transcendental Arguments”. Journal of Philosophy 65, 241-56.

--- 1999: “The Goal of Transcendental Arguments". In: Robert Stern (ed.) Transcendental Arguments: Problems and Prospects. Oxford: Oxford University Press, 155-172.

--- 2000: Understanding Human Knowledge: Philosophical Essays. Oxford: Oxford University Press.

Taylor, Charles 1972: "The Opening Arguments of the Phenomenology". In: Alasdair MacIntyre (ed.) Hegel: A Collection of Critical Essays. Notre Dame: Notre Dame University Press, 151-88.

--- 1987: “Overcoming Epistemology”. In: Kenneth Baynes, James Bonham, and Thomas McCarthy (eds.) After Philosophy: End or Transformation?. Cambridge, Mass: MIT Press, 464-488.

Walker, Ralph C. S. 1978: Kant. London: Routledge. 
--- 1989: "Transcendental Arguments and Scepticism". In: Eva Schaper \& Wilhelm Vossenkuhl (eds.) Reading Kant: New Perspectives on Transcendental Arguments and Critical Philosophy. Oxford: Blackwell, 55-76. 